\title{
Species and age related differences in the type and distribution of influenza virus receptors in different tissues of chickens, ducks and turkeys
}

\author{
Smitha PS Pillai ${ }^{1,2}$, Chang W Lee ${ }^{1,2^{*}}$
}

\begin{abstract}
We undertook one of the most detailed studies on the distribution of $\alpha 2,3$ sialic acid (SA)-galactose (gal) (avian type) and $\alpha 2,65 \mathrm{~A}$-gal (human type) receptors on different tissues of chickens, ducks and turkeys of varying age groups. On the tracheal epithelium, all 3 bird species expressed strong positive staining (80-90\%) for $\alpha 2,3 S A$-gal receptors in the 3 different age groups. In addition, a lesser amount of $\alpha 2,65 \mathrm{~A}$-gal receptors (30-90\%) were observed with slight differences in distribution with age and species. The epithelium of the small and large intestine of turkeys and ducks showed negligible staining for $\alpha 2,6 \mathrm{SA}$-gal receptors whereas the large intestine consistently showed $40-70 \%$ positive staining for $\alpha 2,35 \mathrm{~A}$-gal receptors. In contrast, a greater amount of staining for $\alpha 2,35 A-g a l$ (50-80\%) and $\alpha 2,6 S A-g a l ~(20-50 \%)$ receptors were observed along the epithelium of small and large intestine of chickens. Kidney and esophagus sections from the 3 bird species also expressed both avian and human type receptors. In other tissues examined, brain, breast muscles, bursa, spleen, cecal tonsils and oviduct, human type receptors were absent. Though different viral and receptor components may play roles in successful viral replication and transmission, understanding the receptor types and distribution in different tissues of domestic birds might be good initial tool to understand host factors that promote successful influenza viral infection.
\end{abstract}

\section{Introduction}

Wild aquatic birds are considered to be the natural reservoir of influenza viruses. They have been implicated as the source of influenza viruses for all other species of birds and mammals $[1,2]$. In wild aquatic birds, influenza viruses are believed to have tropism for the digestive tract and follow a fecal oral mode of transmission [3]. Influenza viruses in wild aquatic birds are believed to possess a strict binding preference for sialic acids (SA) linked to galactose (Gal) through $\alpha 2,3$ linkages [4]. Previous immunohistochemical studies using plant lectins revealed the presence of $\alpha 2,3 \mathrm{SA}$-gal residues and no detectable expression of $\alpha 2,6 \mathrm{SA}$-gal receptors in duck intestinal cells [5,6]. Similarly, human viruses were found not to bind to plasma membranes isolated from duck intestinal cells thereby confirming the absence of $\alpha 2,6 \mathrm{SA}$-gal linked sialyloligosaccharides on duck intestinal epithelial cells [5]. Though not natural hosts, many

\footnotetext{
* Correspondence: lee.2854@osu.edu

${ }^{1}$ Food Animal Health Research Program, Ohio Agricultural Research and Development Center, The Ohio State University, Wooster, Ohio 44691, USA
}

land based poultry like chickens, turkeys and quail have been found to support the replication and transmission of a variety of influenza subtypes [7]. Recent studies as well as the human infections caused by $\mathrm{H} 5 \mathrm{~N} 1$ and H9N2 viruses suggested that domestic poultry can be immediate precursors as well as potential intermediate hosts, like pigs, for influenza viruses. $\alpha 2,3 \mathrm{SA}$-gal and $\alpha 2,6 \mathrm{SA}$-gal linked receptors have been detected in the tracheal epithelium of chickens and quail suggesting that they can be infected with avian and mammalian viruses and serve as adaptation hosts for changing the receptor preference of avian viruses from $\alpha 2,3 \mathrm{SA}$-gal to $\alpha 2,6 \mathrm{SA}$-gal [8]. Though turkeys are frequently infected with avian and swine influenza viruses, reports on the receptor profile of tissues from turkeys are lacking. Similarly, few studies have been undertaken to understand the distribution and type of receptors from different tissues of domestic chickens and ducks. Influenza viruses in domestic birds are found to evolve faster than aquatic bird viruses and are characterized by the presence of additional carbohydrates on hemagglutinin and deletions in the stalk of neuraminidases. These findings 
may have implications for the receptor binding and sialidase activity of the virus and suggest that the spectrum of sialic acid containing receptors on different bird species is not identical [5].

Studies on the type and distribution of receptors in different tissues of domestic poultry are still incomplete. In this study, we examined the presence and type of $\alpha 2,3 \mathrm{SA}$-gal and $\alpha 2,6 \mathrm{SA}$-gal receptors on different tissues of domestic poultry that included chickens, ducks and turkeys. We also looked at the age related differences in the distribution of receptors in these 3 bird species.

\section{Materials and methods}

\section{Birds and tissues analyzed}

White Leghorn chickens (Charles River Laboratories, Inc. Wilmington, MA), commercial Pekin ducks (Ridgeway Hatcheries, Inc. LaRue, Ohio) and Eggline turkeys (maintained at Ohio Agricultural Research and Development Center, Wooster, Ohio) of 3 different age groups (1-day-old, 2-4-week-old and 52-60-week-old adult layer birds) were used in the present study. Throughout the study, the birds were handled according to an approved Institutional Animal Care and Use Committee guideline. We collected different tissues that included trachea, lung, spleen, bursa, cecal tonsil, esophagus, portions of small and large intestines, and kidney from the 3 species of birds.

\section{Immunohistochemistry for the detection of receptors using plant lectins}

We examined different tissues of poultry for the presence of receptors by employing two specific lectins, Maackia amurensis agglutinin (MAA) for $\alpha 2,3 \mathrm{SA}$-gal receptors and Sambucus nigra agglutinin (SNA) for $\alpha 2,6$ SA-gal receptors (DIG Glycan Differentiation Kit, Roche Applied Science, Mannheim, Germany). Paraffin embedded tissue sections were deparaffinized and immersed in $3 \%$ hydrogen peroxide to eliminate the endogenous peroxidase activity. The sections were treated with blocking agent to avoid nonspecific staining and then incubated with digoxigenin (DIG)-labelled MAA or SNA $(1 \mu \mathrm{g} / \mu \mathrm{l})$ at $4^{\circ} \mathrm{C}$ overnight. Slides prepared with serial sections of the same tissue were incubated with PBS instead of lectin as negative controls. After two washes in phosphate-buffered saline (PBS), the sections were incubated with peroxidase-labelled anti-DIG FAb fragments (Roche Applied Science) for $1.5 \mathrm{~h}$ at $37^{\circ}$ C. Lectin binding was visualized using DAB (3, 3' -diaminobenzidine-tetrahydrochloride) substrate (Roche diagnostics $\mathrm{GmbH}$, Mannheim, Germany) and slides were counterstained with hematoxylin.

\section{Results}

The receptor distribution in different tissues was determined as the average percentage of positive staining observed by visual examination of 3 different fields of the tissue from at least 3 birds of each species of specific age as observed under $200 \times$ magnification of light microscope. The staining intensity, that correspond to the number of sialic acid moieties stained per cell, was relatively compared and assigned as mild $(+)$, moderate $(++)$, strong $(+++)$ or very strong $(++++)$.

Differences in receptor distribution in the respiratory tracts of chickens, ducks and turkeys with age

In all 3 bird species, the tracheal epithelium showed the predominance of $\alpha 2,3 \mathrm{SA}$-gal receptors. Strong positive staining $(80-90 \%,++++)$ for $\alpha 2,3 \mathrm{SA}$-gal receptors was visible throughout the tracheal epithelial lining in the 3 bird species (Fig. 1). In day-old ducks and chickens, 90\%

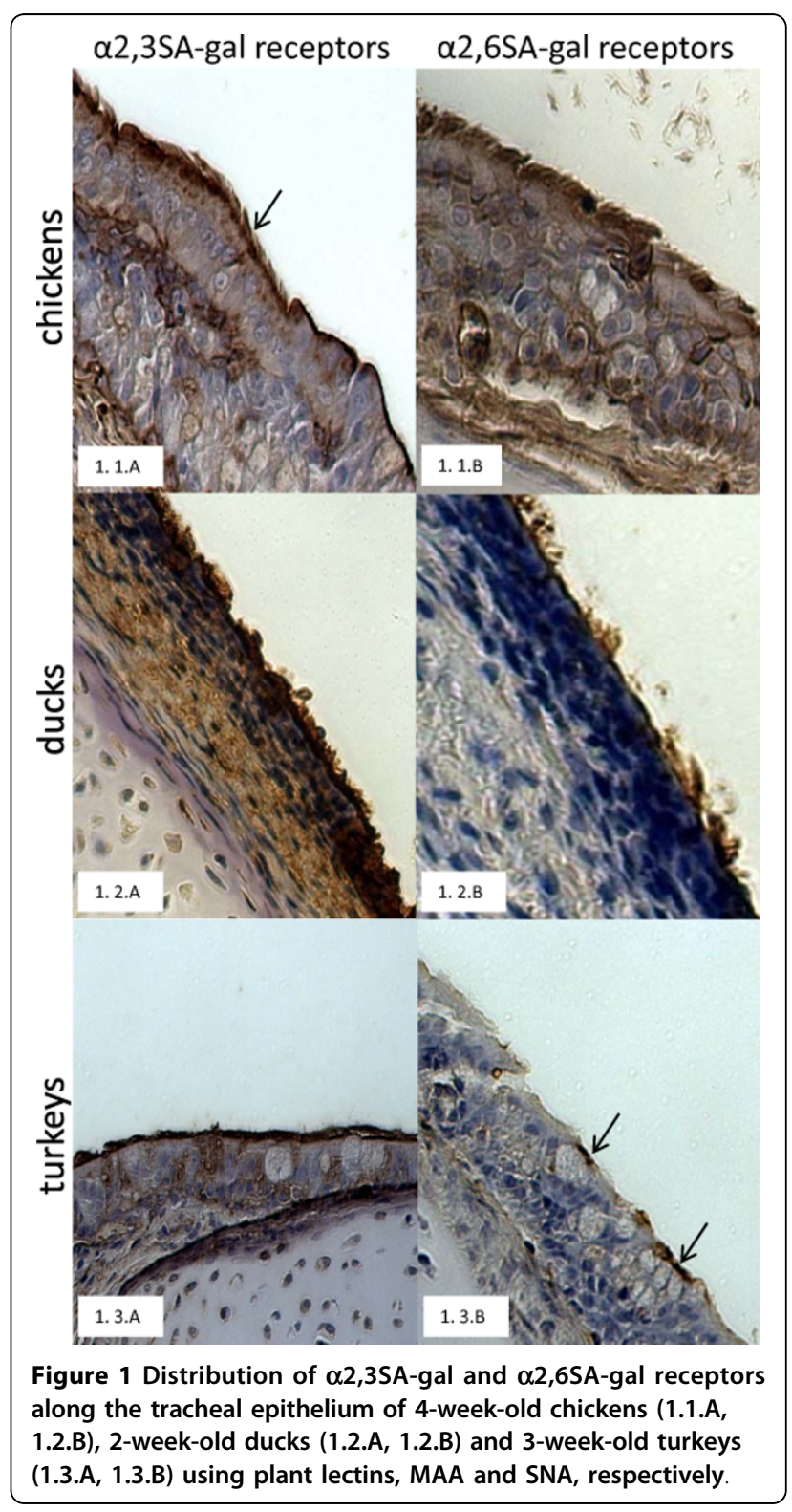




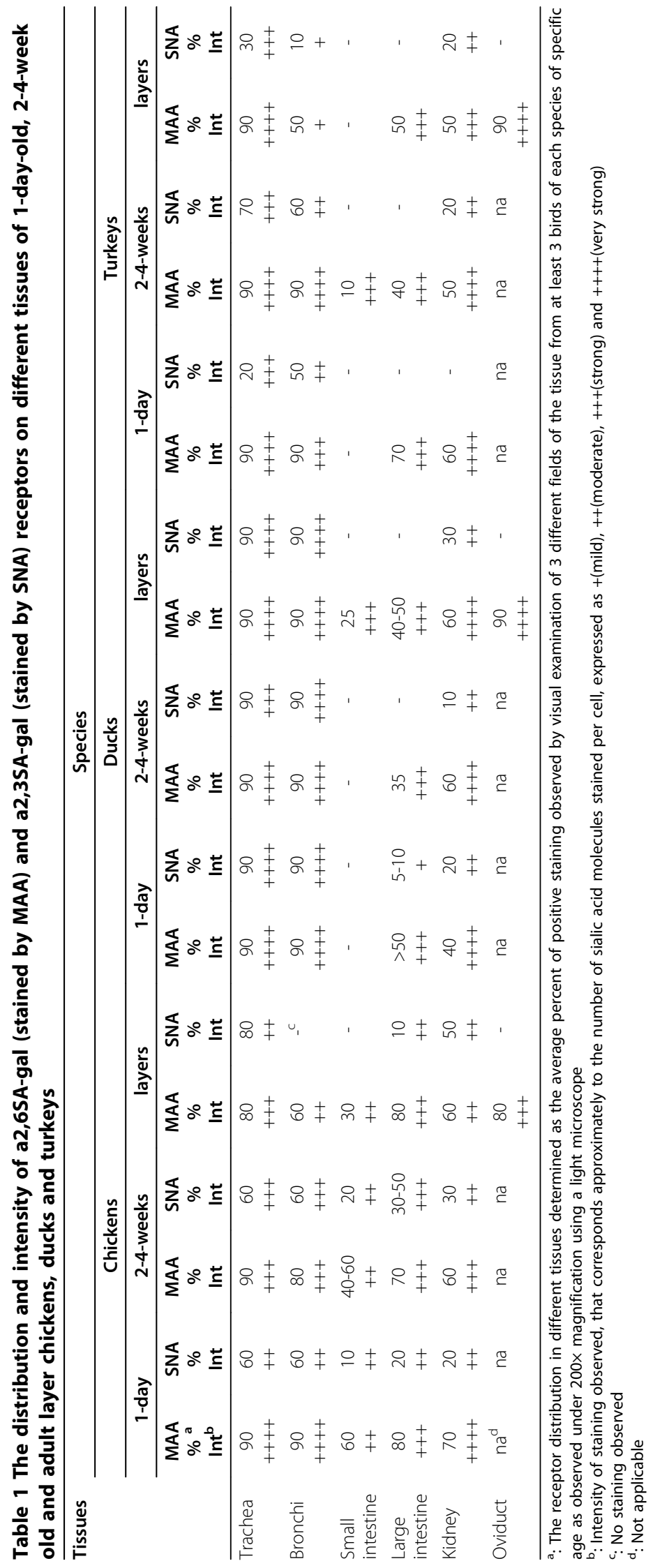


$(+++)$, and $60 \%(++)$ of the lining cells, respectively, were positive for the $\alpha 2,6 \mathrm{SA}$-gal receptors. In contrast, in day-old turkeys, approximately, $20 \%$ of the tracheal epithelial cells showed moderate positive staining $(++)$ for $\alpha 2,6 \mathrm{SA}$-gal receptors (Table 1).

In day-old ducks and chickens, similar results as for trachea were observed for bronchial epithelial cells, with $90 \%$ of the epithelial cells staining positive $(++++)$ for $\alpha 2,3 \mathrm{SA}$-gal receptors and lesser intensity $(+++)$ and fewer percent $(60-90 \%)$ of cells showing positive staining for $\alpha 2,6 \mathrm{SA}$-gal receptors. Minor difference was observed in turkey poults with lower percentage (50\%) of $\alpha 2,6 \mathrm{SA}$ gal receptors on the bronchial epithelium with a lower staining intensity $(++)$.

The respiratory epithelium of 2-4 week old chickens and ducks gave similar results as in 1-day-old birds. However in 2-4 week old turkeys there was an increase of approximately $50 \%$ of cells staining positive for the human type receptors in tracheal epithelium in comparison to the sections from day-old turkey poults.

The $\alpha 2,3$ and $\alpha 2,6 \mathrm{SA}$-gal receptor distribution in the trachea, bronchi and lungs of layer ducks was similar to the distribution in 1-day-old as well as 2-4-week-old ducks. In chickens, an increase (from $60 \%$ to $80 \%$ positive cells); and in turkeys, a decrease (from $70 \%$ to $30 \%$ positive cells) in staining for $\alpha 2,6 \mathrm{SA}$-gal receptors was observed along the tracheal epithelium. The bronchial epithelium of layer chickens did not show the presence of human type receptors. With the exception of bronchial epithelium, sections prepared from different parts of the lung were negative for the presence of both $\alpha 2,3 \mathrm{SA}$-gal or $\alpha 2,6 \mathrm{SA}$-gal receptors in different age groups of the 3 bird species.

\section{Differences in receptor distribution along the epithelium of small and large intestine of chickens, ducks and turkeys with age}

In day old ducks, less than $5 \%(+++)$ of the epithelial cells of small intestine showed positive staining for the avian type receptors with no detectable presence of human type receptors while no staining for both receptors was observed in turkey poults. In contrast, in dayold chickens, approximately $60 \%(++)$ positive staining was observed for $\alpha 2,3 \mathrm{SA}$-gal receptors, with less positive staining $(10 \%,++)$ for $\alpha 2,6 \mathrm{SA}$-gal receptors.

The epithelial cells of large intestine showed the presence of avian type receptors in day-old birds of all 3 species, with chickens also showing the presence of mammalian receptors $(20 \%,++)$. The distribution of the avian receptors varied from $40-70 \%$ in most of the epithelial cells of large intestine in the 3 bird species (Table 1).

We did not observe the presence of either type of receptors in the epithelium of small intestine of 2-weekold ducks. However with 3-week-old turkeys, epithelial cells from jejunum and ileum showed positive staining for avian type receptors $(10 \%,+++)$. In 3-week-old chickens, epithelial cells of jejunum $(40 \%,++)$ and ileum $(60 \%,+++)$ showed higher percentage of positive staining for $\alpha 2,3 S A-g a l$ receptors. The epithelial cells from ileum of chickens also showed presence of $\alpha 2,6 \mathrm{SA}$-gal receptors $(20 \%,++)$.

The epithelial cells of large intestine showed $30-50 \%$ staining $(+++)$ for the presence of $\alpha 2,3 \mathrm{SA}$-gal receptors in 2-week-old ducks and turkeys with no positive staining for human type receptors. In 4-week-old chickens, along the epithelium of large intestine, a higher percentage of positive staining $(70 \%,+++)$ was observed for avian type receptors along with the presence of human type receptors (30-50\%, +++) (Fig. 2).

The epithelial cells of small intestine of layer chickens and ducks showed positive staining for avian receptors $(25-30 \%,+++)$, however, sections of small intestine from breeder turkeys were negative for the presence of avian type receptors. Layer chickens showed higher percentage of positive staining for avian type receptors along the epithelium of large intestine $(80 \%,+++)$ in comparison to ducks $(40-50 \%,++$ to +++$)$ or turkeys $(50 \%,+++)$. No human type receptors were observed in small or large intestine.

\section{Differences in distribution of receptors in other tissues examined}

In day-old birds, the tubular cells of the kidney showed positive staining for $\alpha 2,3 \mathrm{SA}$-gal and $\alpha 2,6 \mathrm{SA}$-gal receptors in the 3 bird species. Approximately, $40-70 \%$ of the cells showed very strong positive staining $(++++)$ for the presence of avian type receptors. Less than $30 \%$ of the cells were positive for $\alpha 2,6 \mathrm{SA}$-gal receptors and the staining intensity was moderate $(++)$.

Similar to the 1-day-old birds, the 2-4-week-old birds and layer birds of the 3 species showed strong staining $(++$ $++)$ in the tubular cells of the kidney (50-60\%) for the avian type receptors. The tubular cells also showed positive staining for the human type receptors, although the strained cells was less (10-30\%) and mild to moderate intensity (+ to ++ ) of staining was observed (Fig. 3A and 3B).

Among the layer birds of the 3 species tested, all the sections of the oviduct including the infundibulum, magnum, isthmus and the uterus showed high intensity of positive staining $(80-90 \%,++++)$ for the avian type receptors. These sections did not give any positive staining for the human type receptors. Results of receptor staining for turkey oviduct sections were previously reported [9].

No human type receptors were detected in other organ sections (brain, breast muscles, bursa, spleen, and cecal tonsils) tested. In the brain, positive staining for avian type receptors was found in the meningeal layer surrounding the brain (Fig. 3F). The sections of the 


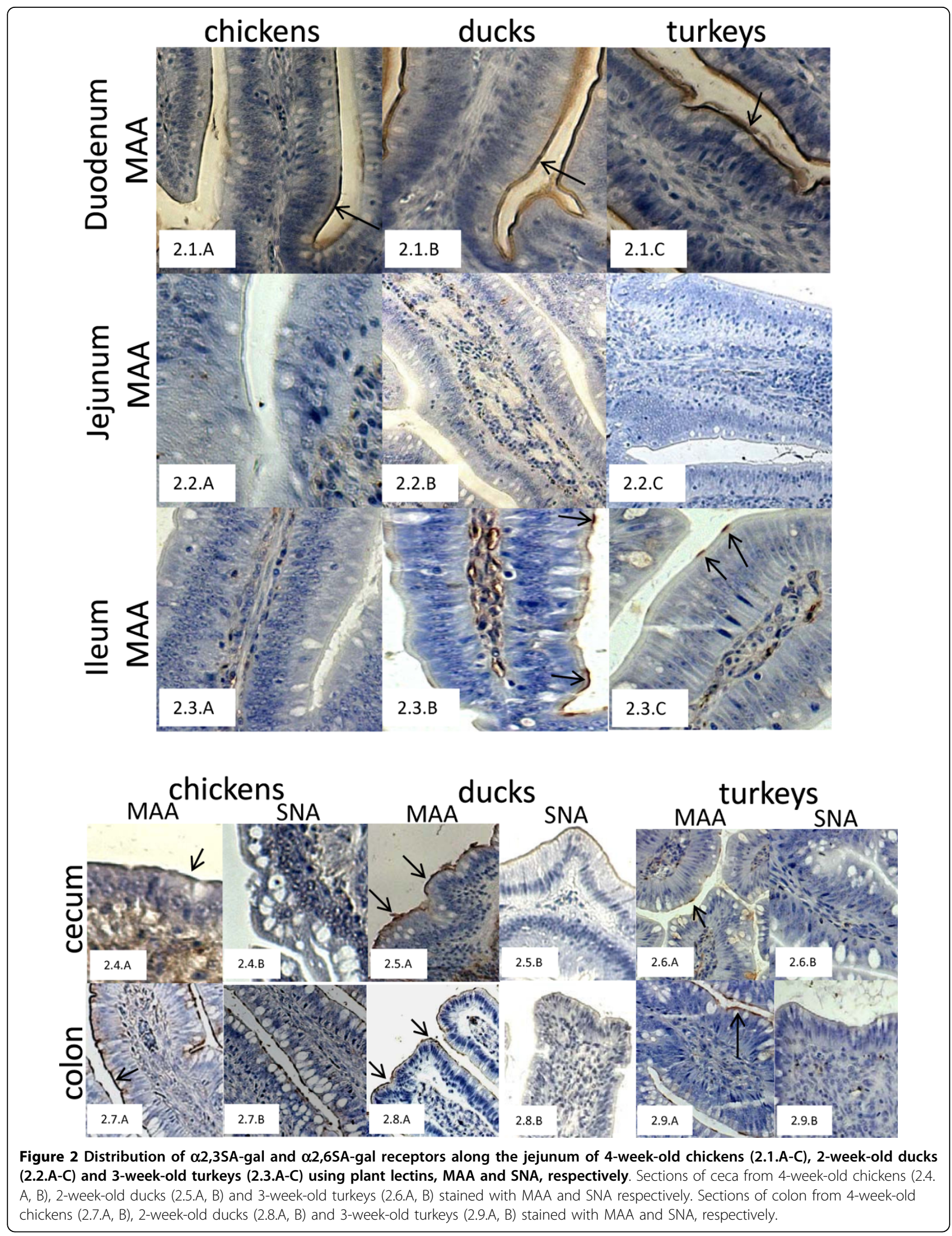




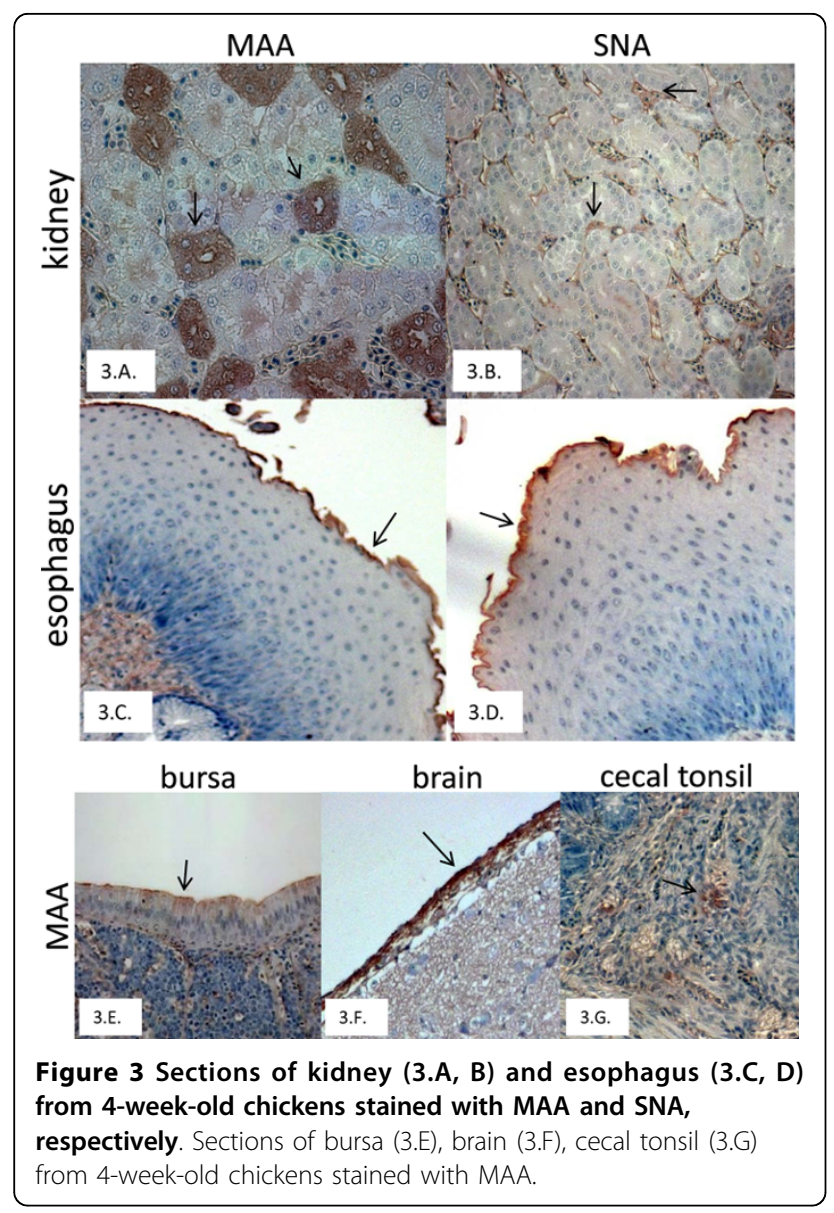

esophagus gave strong positive staining for both avian and human type receptors along the mucosal epithelium (Fig. 3C and 3D). Though influenza viral replication has been demonstrated in muscles and lymphoid tissues (bursa, thymus and spleen) by immunohistochemistry, avian or human type receptors were not detected in these tissue sections.

\section{Discussion}

Influenza viruses attach to host cells through interactions of the viral hemagglutinin with sialic acid terminated oligosaccharide residues on host cells. These interactions determine to a large extent the host range and successful interspecies transmission of influenza viruses [10]. Sialic acids, a family of 9-carbon acid sugars were identified and are still believed to be major receptor determinants of influenza viruses [11]. Using specific sialic acid determinants generated by sialyltransferases, human and avian viruses were found to preferentially bind to $\alpha 2,6 \mathrm{SA}$-gal (human type) and $\alpha 2,3 \mathrm{SA}$-gal (avian type) receptors, respectively $[12,13]$.

The presence of avian and human type receptors on the tracheal epithelium of the 3 species of birds even at one day of age, indicate that both avian and human influenza viruses may utilize these receptors for binding to initiate infections. The presence of avian receptors in the trachea and bronchial epithelium and their absence in other parts of lung support previous findings that influenza viruses mainly localize in the upper respiratory tracts in domestic birds [1]. Chicken tracheal epithelial cells have been previously shown to posses both types of receptors and chickens have been proposed to be potential intermediate hosts in the interspecies transmission of influenza viruses [14].

Equal intensity of strong positive staining for avian and human type receptors observed in the trachea of ducks of the 3 age groups was an interesting finding, especially considering the dominant presence of $\alpha 2,3 \mathrm{SA}$-gal receptors in epithelial cell of the large intestine. The presence of avian type receptors on the tracheal epithelium of ducks is supported by their susceptibility to low and highly pathogenic influenza viruses and successful oropharyngeal shedding [15]. Also surveillance studies report high rates of viral recovery from tracheal swabs similar to cloacal swabs from ducks $[1,16,19]$. A recent study employing immunoflourescence staining also indicated the presence of $\alpha 2,3 \mathrm{SA}$-gal and $\alpha 2,6 \mathrm{SA}$-gal receptors on duck tracheal epithelial cells [20].

With turkeys, studies on the receptor distribution profile from the tracheal epithelium are lacking. Turkeys have been found to be naturally and experimentally infected with influenza viruses of avian and mammalian origins $[16,21,25]$. The presence of avian and human type receptors in turkeys along with their higher susceptibility to wild and domestic bird origin and swine viruses strengthens the argument that turkeys, like chickens and quail can be potential intermediate hosts for interspecies transmission and spread of reassortant viruses between birds and humans.

Differences in percent staining of avian and human type receptors were seen along the tracheal epithelia in different age groups of chickens, ducks and turkeys. However, it is not clear if such percentages have an effect on the infection with viruses from different sources or if a minimum percent of receptors is enough to initiate infections.

The distribution and intensity of receptors in the bronchial epithelium of the 3 bird species was similar to the results observed for tracheal epithelium. Failure to detect receptors in different parts of the lung tissues does not indicate absence of influenza virus replication in lung tissues of domestic birds. Many high and low pathogenic influenza virus infections of domestic and live bird market poultry have been found to infect lungs and viral antigen has been demonstrated in lungs tissues $[26,27]$. The presence of lung infection in conjunction 
with failure to detect receptors might indicate that the distribution of receptors in the respiratory tract might not be as clear cut as we observe using lectin histochemistry and that other host and viral components might play a role $[28,29]$.

With the intestinal sections, only chicken intestinal epithelial cells exhibited avian and human type receptors among the 3 bird species tested. With turkeys and ducks, only avian type receptors were predominant and were mostly restricted to the large intestine. Few previous reports indicate high frequency of viral isolation from cloaca, jejunum and ileum following experimental inoculation of wild waterfowl origin viruses in chickens $[17,30]$. Our results are in agreement with previous studies that reported the presence of $\alpha 2,3-$ and $\alpha 2,6 \mathrm{SA}$-gal receptors on chicken colon [31] and absence of SNA staining in duck intestinal cells [6]. Also, chicken duodenum was not found to express $\alpha 2,6 \mathrm{SA}$-gal receptors as previously reported [27]. Studies by Wan and Perez [8] reported large amounts of positive cells for $\alpha 2,3 \mathrm{SA}$-gal residues along the chicken duodenal sections, especially in crypts. Our study revealed positive staining for $\alpha 2,3 \mathrm{SA}$-gal receptors along the jejunum and ileum and $\alpha 2,6 \mathrm{SA}$-gal receptors in ileal sections of chicken intestines, with no positive staining for either type of receptors along the duodenal sections of chickens. We do not know if such discrepancies in results were due to the different MAA isoforms that were employed in these studies. The use of different breeds of birds within the same species as well as differences in tissue processing techniques may also account for the different staining results observed.

Kidney sections from the 3 bird species were found to be positive for the presence of avian and human type receptors. Many influenza viruses have been found to be nephrotropic following infection [9,32,33]. Madin Darby canine kidney (MDCK) cell line and primary chicken embryonic kidney cells have been found to support efficient replication of influenza viruses [34]. Our results indicate that kidney cell lines from domestic poultry of the 3 age groups that we studied could be used for influenza viral propagation. This may offer the additional advantage of species specificity with the avian cell lines and use of adult birds in place of chicken embryos alone for viral propagation. In addition to kidney, we observed the presence of both avian and human type receptors along the esophageal mucosa indicating that influenza viruses can attach and possibly replicate in the upper digestive tract which is an important portal of viral entry and supports the fecal-oral transmission route of influenza viruses.

The oviduct from all species of birds showed the presence of $\alpha 2,3 \mathrm{SA}$-gal linked receptors. Influenza infections have been associated with lowered egg production in layer chickens and breeder turkeys [9,17]. It is possible that the viruses utilize the $\alpha 2,3$ linked sialic acid receptors in the oviduct for binding and subsequent infections. Our previous studies in breeder turkeys using a triple reassortant turkey virus, A/turkey/Ohio/04 (H3N2), showed that the virus preferentially replicates in the oviduct of breeder turkeys in comparison to the respiratory or digestive tracts and result in drastic declines in egg production in breeder turkeys [9]. This study also showed an exact match between the presence of $\alpha 2,3 \mathrm{SA}$-gal receptors and viral antigen in duplicate sections of the oviduct indicating that the viruses might utilize these receptors for virus-cell interactions.

The absence of receptors in tissues like spleen, brain, cecal tonsils analyzed in this study does not necessarily indicate absence of infection with influenza viruses especially following infection with highly pathogenic isolates indicating again that receptor distribution might not be as clear cut as observed with lectin immunonochemistry. Highly pathogenic avian influenza isolates have been found to consistently localize to brain and pancreas of infected birds $[24,35,36]$. Viral antigen has also been demonstrated from muscle tissues of experimentally infected ducks [37]. A high frequency of viral recovery has been demonstrated from the bursa of chickens following experimental inoculation using waterfowl origin influenza viruses [27]. Experimental inoculation of highly pathogenic viruses into chickens has revealed histological lesions consisting of necrosis and inflammation in cloacal bursa, thymus, spleen, heart muscle, brain along with lesions in pancreas and lung tissues [27]. Highly pathogenic avian influenza viruses have also been isolated from duck meat following infection [19]. Even in the demonstrable absence of receptors, documentation of viral replication in these organs indicate that yet to be known receptor determinants might be involved. These findings also indicate the shortcomings of receptor studies using lectin histochemistry. Nevertheless, the presence of $\alpha 2,3 \mathrm{SA}$-gal and $\alpha 2,6 \mathrm{SA}$-gal receptors along their tracheal epithelium, bronchus, esophagus, and intestinal tract might indicate the possibility of adaptation of wild bird viruses in domestic turkeys, ducks and chickens and occasional emergence of viruses with different receptor preference and an enhanced propensity for transmission to different species.

\section{Acknowledgements}

We would like to thank Megan Strother, Keumsuk Hong, and Dr. Kwonil Jung for their technical assistance with this work. This work was supported in part by the USDA-ARS Specific Cooperative Agreement (\# 58-6612-6-237).

\section{Author details}

${ }^{1}$ Food Animal Health Research Program, Ohio Agricultural Research and Development Center, The Ohio State University, Wooster, Ohio 44691, USA. 
${ }^{2}$ Department of Veterinary Preventive Medicine, College of Veterinary Medicine, The Ohio State University, Columbus, Ohio 43210, USA.

\section{Authors' contributions}

SPSP participated in the design of the study, performed the study, read the immunohistochemistry slides, and drafted the manuscript. CWL conceived of the study, participated in its design and coordination, and completed the manuscript. All authors read and approved the final manuscript.

\section{Competing interests}

The authors declare that they have no competing interests.

Received: 13 October 2009

Accepted: 12 January 2010 Published: 12 January 2010

\section{References}

1. Alexander DJ: A review of avian influenza in different bird species. Vet Microbiol 2000, 74:3-13.

2. Webster RG: Influenza: an emerging disease. Emerg Infect Dis 1998, 4:436441.

3. Hinshaw VS, Webster RG, Turner B: Water-borne transmission of influenza A viruses?. Intervirology 1979, 11:66-68.

4. Gambarian AS, lamnikova SS, L'Vov D K, Robertson JS, Webster RG, Matrosovich MN: [Differences in receptor specificity between the influenza $A$ viruses isolated from the duck, chicken, and human]. Mol Biol (Mosk) 2002, 36:542-549.

5. Gambaryan A, Webster R, Matrosovich M: Differences between influenza virus receptors on target cells of duck and chicken. Arch Virol 2002, 147:1197-1208.

6. Ito T, Couceiro JN, Kelm S, Baum LG, Krauss S, Castrucci MR, Donatelli I, Kida H, Paulson JC, Webster RG, Kawaoka Y: Molecular basis for the generation in pigs of influenza A viruses with pandemic potential. J Virol $1998,72 \cdot 7367-7373$.

7. Liu M, Guan Y, Peiris M, He S, Webby RJ, Perez D, Webster RG: The quest of influenza A viruses for new hosts. Avian Dis 2003, 47:849-856.

8. Wan H, Perez DR: Quail carry sialic acid receptors compatible with binding of avian and human influenza viruses. Virology 2006, 346:278-286

9. Pillai SP, Pantin-Jackwood M, Jadhao SJ, Suarez DL, Wang L, Yassine HM, Saif YM, Lee CW: Pathobiology of triple reassortant H3N2 influenza viruses in breeder turkeys and its potential implication for vaccine studies in turkeys. Vaccine 2009, 27:819-824

10. Matrosovich M, Zhou N, Kawaoka Y, Webster R: The surface glycoproteins of $\mathrm{H} 5$ influenza viruses isolated from humans, chickens, and wild aquatic birds have distinguishable properties. J Virol 1999, 73:1146-1155.

11. Klenk $E$, Faillard $H$, Lempfrid $H$ : [Enzymatic effect of the influenza virus.]. Hoppe Seylers Z Physiol Chem 1955, 301:235-246.

12. Carroll SM, Higa HH, Paulson JC: Different cell-surface receptor determinants of antigenically similar influenza virus hemagglutinins. J Biol Chem 1981, 256:8357-8363.

13. Rogers GN, Paulson JC: Receptor determinants of human and animal influenza virus isolates: differences in receptor specificity of the $\mathrm{H} 3$ hemagglutinin based on species of origin. Virology 1983, 127:361-373.

14. Gambaryan AS, Tuzikov AB, Piskarev VE, Yamnikova SS, Lvov DK Robertson JS, Bovin NV, Matrosovich MN: Specification of receptor-binding phenotypes of influenza virus isolates from different hosts using synthetic sialylglycopolymers: non-egg-adapted human $\mathrm{H} 1$ and $\mathrm{H} 3$ influenza $A$ and influenza $B$ viruses share a common high binding affinity for 6'-sialyl(N-acetyllactosamine). Virology 1997, 232:345-350.

15. Brown JD, Stallknecht DE, Beck JR, Suarez DL, Swayne DE: Susceptibility of North American ducks and gulls to H5N1 highly pathogenic avian influenza viruses. Emerg Infect Dis 2006, 12:1663-1670.

16. Alexander DJ, Allan WH, Parsons DG, Parsons G: The pathogenicity of four avian influenza viruses for fowls, turkeys and ducks. Res Vet Sci 1978, 24:242-247.

17. Alexander DJ, Lister SA, Johnson MJ, Randall CJ, Thomas PJ: An outbreak of highly pathogenic avian influenza in turkeys in Great Britain in 1991. Vet Rec 1993, 132:535-536.

18. Kida $\mathrm{H}$, Yanagawa $\mathrm{R}$, Matsuoka $\mathrm{Y}$ : Duck influenza lacking evidence of disease signs and immune response. Infect Immun 1980, 30:547-553.

19. Tumpey TM, Suarez DL, Perkins LE, Senne DA, Lee JG, Lee YJ, Mo IP, Sung HW, Swayne DE: Characterization of a highly pathogenic $\mathrm{H} 5 \mathrm{~N} 1$ avian influenza A virus isolated from duck meat. J Virol 2002, 76:6344 6355

20. Kuchipudi SV, Nelli R, White GA, Bain M, Changand KC, Dunham S: Differences in influenza virus receptors in chickens and ducks: Implications for interspecies transmission. J Mol Genet Med 2009, 3:143151

21. Webster RG, Bean WJ, Gorman OT, Chambers TM, Kawaoka Y: Evolution and ecology of influenza A viruses. Microbiol Rev 1992, 56:152-179.

22. Alexander DJ, Parsons G, Manvell RJ: Experimental assessment of the pathogenicity of eight avian influenza A viruses of H5 subtype for chickens, turkeys, ducks and quail. Avian Pathol 1986, 15:647-662.

23. Andral B, Toquin D, Madec F, Aymard M, Gourreau JM, Kaiser C, Fontaine M, Metz MH: Disease in turkeys associated with $\mathrm{H} 1 \mathrm{~N} 1$ influenza virus following an outbreak of the disease in pigs. Vet Rec 1985, 116:617-618.

24. Ladman BS, Rosenberger SC, Rosenberger JK, Pope CR, Gelb J Jr: Virulence of low pathogenicity H7N2 avian influenza viruses from the Delmarva peninsula for broiler and leghorn chickens and turkeys. Avian Dis 2008, 52:623-631.

25. Swayne DE, Slemons RD: Using mean infectious dose of high- and lowpathogenicity avian influenza viruses originating from wild duck and poultry as one measure of infectivity and adaptation to poultry. Avian Dis 2008, 52:455-460.

26. Choi YK, Seo SH, Kim JA, Webby RJ, Webster RG: Avian influenza viruses in Korean live poultry markets and their pathogenic potential. Virology 2005, 332:529-537.

27. Mo IP, Brugh M, Fletcher OJ, Rowland GN, Swayne DE: Comparative pathology of chickens experimentally inoculated with avian influenza viruses of low and high pathogenicity. Avian Dis 1997, 41:125-136.

28. Barkhordari A, Stoddart RW, McClure SF, McClure J: Lectin histochemistry of normal human lung. J Mol Histol 2004, 35:147-156.

29. Nicholls JM, Chan RW, Russell RJ, Air GM, Peiris JS: Evolving complexities of influenza virus and its receptors. Trends Microbiol 2008, 16:149-157.

30. Matrosovich M, Tuzikov A, Bovin N, Gambaryan A, Klimov A, Castrucci MR, Donatelli I, Kawaoka Y: Early alterations of the receptor-binding properties of $\mathrm{H} 1, \mathrm{H} 2$, and $\mathrm{H} 3$ avian influenza virus hemagglutinins after their introduction into mammals. J Virol 2000, 74:8502-8512.

31. Guo CT, Takahashi N, Yagi H, Kato K, Takahashi T, Yi SQ, Chen Y, Ito T,

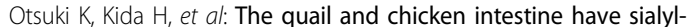
galactose sugar chains responsible for the binding of influenza A viruses to human type receptors. Glycobiology 2007, 17:713-724.

32. Slemons RD, Condobery PK, Swayne DE: Assessing pathogenicity potential of waterfowl-origin type A influenza viruses in chickens. Avian Dis 1991, 35:210-215.

33. Slemons RD, Swayne DE: Tissue tropism and replicative properties of waterfowl-origin influenza viruses in chickens. Avian Dis 1995, 39:521-527.

34. Lee CW, Jung K, Jadhao SJ, Suarez DL: Evaluation of chicken-origin (DF-1) and quail-origin (QT-6) fibroblast cell lines for replication of avian influenza viruses. J Virol Methods 2008, 153:22-28.

35. Perkins LE, Swayne DE: Susceptibility of laughing gulls (Larus atricilla) to $\mathrm{H} 5 \mathrm{~N} 1$ and $\mathrm{H} 5 \mathrm{~N} 3$ highly pathogenic avian influenza viruses. Avian Dis 2002, 46:877-885.

36. Perkins LE, Swayne DE: Varied pathogenicity of a Hong Kong-origin H5N1 avian influenza virus in four passerine species and budgerigars. Vet Pathol 2003, 40:14-24.

37. Vascellari M, Granato A, Trevisan L, Basilicata L, Toffan A, Milani A, Mutinelli F: Pathologic findings of highly pathogenic avian influenza virus $A /$ Duck/Vietnam/12/05 (H5N1) in experimentally infected pekin ducks, based on immunohistochemistry and in situ hybridization. Vet Pathol 2007, 44:635-642.

doi:10.1186/1743-422X-7-5

Cite this article as: Pillai and Lee: Species and age related differences in the type and distribution of influenza virus receptors in different tissues of chickens, ducks and turkeys. Virology Journal 2010 7:5 